\title{
Latihan Teknik Dasar Sepak Bola Usia 14-15 Tahun
}

\author{
Aprilianto, Roesdiyanto*, Taufik \\ Universitas Negeri Malang, Jl. Semarang No. 5 Malang, Jawa Timur, Indonesia \\ *Penulis korespondens, Surel: roesdiyanto.fik@um.ac.id
}

Paper received: 6-2-2022; revised: 24-2-2022; accepted: 29-2-2022

\begin{abstract}
The aim of the researcher in this research and development is to produce a basic soccer technique training model for SSB Satria Muda Malang City. The research method used in this study is Research and Development (R\&D). The instruments used in this research are interviews and questionnaires. The data analysis technique in this study used qualitative and quantitative descriptive. This study was validated by 3 football coaching experts who obtained $99.57 \%$ results. The results of this research and development concluded that the basic soccer technique training model was very good and could be used for athletes aged 14-15 years at SSB Satria Muda Malang City.
\end{abstract}

Keywords: training model; soccer basic technique

\begin{abstract}
Abstrak
Tujuan peneliti dalam penelitian dan pengembangan ini adalah menghasilkan model latihan teknik dasar sepakbola untuk SSB Satria Muda Kota Malang. Metode penelitian yang digunakan dalam penelitian ini yaitu Research and Development (R\&D). Instrumen yang digunakan dalam penelitian ini yaitu wawancara dan angket. Teknik analisis data pada penelitian ini menggunakan deskriptif kualitatif dan kuantitatif. Penelitian ini melalui validasi 3 ahli kepelatihan sepakbola yang memperoleh hasil 99, $57 \%$. Hasil dari penelitian dan pengembangan ini disimpulkan bahwa model latihan teknik dasar sepak bola sangat baik dan dapat digunakan untuk atlet usia 14-15 tahun SSB Satria Muda Kota Malang.
\end{abstract}

Kata kunci: model latihan; teknik dasar sepakbola

\section{Pendahuluan}

suatu aktivitas yang dilakukan secara sistematis disebut olahraga. Olahraga memiliki tujuan yaitu menyehatkan jasmani dan rohani. (Bangun, 2016) menyatakan olahraga yaitu aktivitas pelatihan jasmani, dengan kegiatan untuk memperluas atau meningkatkan kemampuan, keterampilan gerak dasar dalam berolahraga kemudian (Khairuddin, 2017) menyatakan olahraga sebagai bentuk aktivitas fisik dan mental yang bermanfaat mempertahankan dan meningkatkan kualitas seseorang. Di lingkungan masyarakat, olahraga sudah tidak asing lagi. Ada banyak macam kegiatan olahraga baik dalam ruangan maupun diluar ruangan contohnya seperti sepakbola, futsal, bola voli, renang, tetapi ada satu olahraga yang belakangan ini mengalami perkembangan yang cukup pesat, yaitu sepakbola sedangkan (Ferianto et al., 2020) olahraga yaitu salah satu tumpuan utama untuk mendorong gerak dasar setiap orang.

Sepak bola sudah dimainkan sejak lama di berbagai negara, Meskipun setiap negara memiliki nama yang berbeda tetapi sepak bola mempunyai tujuan yang sama. Tujuan sepakbola yaitu permainan yang bisa dimainkan oleh dua tim yang masing-masing tim terdiri dari 11 pemain, setiap tim akan berusaha memainkan bola dan menjaga bola supaya tidak direbut oleh lawan dengan tujuan akhir memasukan bola ke gawang lawan untuk memperoleh 
skor. Seperti dinyatakan (Syukur \& Soniawan, n.d.) sepakbola adalah suatu permainan yang harus memiliki banyak energi, memiliki kepintaran saat berada di lapangan sehingga memunculkan semangat, sehingga memberikan kesenangan dalam sebuah tim. sedangkan Septian Nosa, bahwa sepakbola merupakan salah satu cabang olahraga yang dimainkan secara beregu atau tim, dimana tim atau regu yang bermain baik dan disiplin yang akan mampu melakukan permainan yang solid dan struktur yang artinya tim atau regu memiliki kerjasama yang baik (Septian nosa, 2013) Sepak bola termasuk kedalam olahraga yang digemari banyak orang dan memiliki perkembangan yang cepat. Di dalam buku nya Danurwindo menyatakan di Indonesia saat ini memiliki perkembangan pemain bola begitu pesat, hal tersebut dibuktikan melalui ditemukannya banyak sekolah-sekolah sepak bola (SSB) yang di buat di berbagai daerah di indonesia '(Danurwindo et al., 2017).

Sepakbola berkembang sangat besar dan memiliki pengaruh sangat kuat, oleh karena itu semua pemain dituntut untuk lebih meningkatkan kemampuannya. Kemampuan yang ditingkatkan akan membantu pemain untuk lebih tampil maksimal. Seorang pemain sepakbola agar dapat bermain dengan maksimal harus memiliki kemampuan teknik dasar, fisik dan mental yang baik seperti yang dinyatakan oleh Qohhar dan Pazriansyah kemampuan menguasai teknik dasar dalam permainan sepakbola sangat penting karena dapat menunjang penampilan atlet dalam sebuah pertandingan sepakbola baik secara individu atau secara kolektif (Qohhar \& Pazriansyah, 2019) Dalam olahraga sepakbola, pemain diharuskan menguasai semua teknik dasar sepakbola ini bertujuan supaya pemain dapat bermain dengan baik. Teknik dasar dalam sepakbola meliputi menendang bola, menggiring bola, menyundul bola, mengumpan bola, dan menghentikan bola. Sama halnya menurut (Saputra et al., 2019) teknik dasar yaitu semua aktivitas yang mendasar permainan dengan model seperti itu atlet sudah bisa bermain sepakbola. Hal tersebut seperti dinyatakan (Amiq, 2016) dalam bukunya yang menyebutkan macam-macam teknik dasar sepakbola yaitu passing (mengumpan bola), shooting (menendang bola), heading (menyundul bola) controlling (menghentikan bola), dribbling (mengiring bola).untuk menguasai teknik dasar yang baik diperlukan adanya latihan. Amiq menyatakan pemain perlu melakukan latihan untuk dapat menguasai teknik dasar maupun strategi dalam sepakbola supaya pemain lebih berkembang permainannya.

Latihan sepak bola suatu aktivitas yang dilaksanakan dengan terencana dan terstruktur yang mana didalam latihan terdapat tujuan meningkatkan keterampilan teknik maupun fisik seorang siswa dalam meningkatkan prestasi yang paling tinggi. (Amiq, 2016), juga menyatakan latihan ialah suatu proses untuk mempersiapkan olahragawan yang dilakukan dengan sistematis dan berulang-ulang dengan semakin meningkatnya beban yang diberikan. Menurut (Chan, 2012) latihan adalah salah satu aktivitas yang terstruktur dan terencana dalam meningkatkan gerak tubuh. Dalam artikelnya palar berpendapat Latihan ialah proses aktivitas yang dilaksanakan dengan sistematis serta berkesinambungan, dengan memberikan Beban atau intensitas yang semakin bertambah setiap harinya sehingga dapat membuat perubahan secara menyeluruh kepada tubuh (Palar et al., 2015).

Dalam kondisi perkembangan sepakbola modern serta ditengah halangan yang menyerang, semua Pembina sekolah sepakbola (SSB) yang ada harus memiliki peran yang lebih optimal. Praktis sekolah sepakbola (SSB) menjadi wadah untuk anak-anak serta remaja yang mempunyai ingin untuk belajar sepakbola. Menurut (Wibowo, 2012) pembinaan yang baik harus memiliki penyusunan strategi atau rancangan sehingga menghasilkan kualitas dan mempunyai program yang bertujuan untuk membentuk karakter atlet sehingga bisa memiliki 
kualitas yang baik. (Danurwindo et al., 2017) adapun hal-hal yang diberikan dalam binaan sekolah sepakbola (SSB) yaitu mulai dari teknik-teknik dasar dalam sepakbola sampai wawasan dalam permainan sepakbola.

Sekolah sepakbola (SSB) tidak terlepas dari peran seorang pelatih, menurut (Fadli, 2019) Sekolah sepakbola adalah wadah olahraga khusus sepakbola bertujan memiliki peran untuk mengembangkan potensi atlet. Pelatih merupakan faktor penting untuk perkembangan prestasi dan bakat yang dimiliki anak didiknya. Karena seorang pelatih bukan hanya harus memiliki wawasan yang sangat banyak tentang sepakbola. Seorang pelatih juga harus bisa menerapkan wawasan kepada anak didiknya. Adapun beberapa aspek yang harus dikembangkan oleh seorang pelatih adalah mampu mengembangkan aspek fisik, teknik, taktik dan mental anak-anak didiknya.dari aspek-aspek inilah yang dapat memudahkan seorang anak didiknya dapat mencapai prestasi yang optimal sedangkan (Ujang Rohman, 2017) pelatih yaitu salah satu pendorong untuk keberhasilan atlet agar mencapai prestasi.

Seperti halnya cabang-cabang olahraga lain, didalam permainan sepakbola juga terdapat teknik dasar. Teknik dasar yang perlu dipelajari pada sepakbola adalah seperti mengumpan (passing), menahan bola (control), menggiring (dribbling), menendang bola ke gawang (shooting) dan menyundul bola (heading). Adapun pengertian teknik dasar tersebut adalah, passing merupakan suatu teknik untuk memindahkan bola dari suatu tempat ketempat lain sehingga mengakibatkan bola berpindah (Simanjorang et al., 2020). Pengerti passing lainnya yaitu passing merupakan suatu seni dalam permainan sepak bola untuk menciptakan atau memindahkan peluang dari satu titik ke titik lain (Santoso, 2014). Kemudian control merupakan teknik untuk menahan bola yang datang nya bergulir di tanah, memantul, maupun pun yang datang di udara yang bisa di lakukan dengan menggunakan kaki bagian dalam maupun luar (Julianto, A. R., Rusmiati, P., \& Suryadi, 2019).

Menurut Aprianova dribbling merupakan bagian penting dari teknik dasar yang sangat di perlukan oleh semua pemain sepak bola (Aprianova, F., \& Hariadi, 2017). Pengertian dribbling yaitu teknik memindahkan bola dari satu posisi keposisi lain dengan membawa bola menggunakan kaki bagian tertentu (Saputra, M. R. E., \& Yunus, 2019). Sedangkan pengertian dribbling lainnya yaitu dribbling adalah teknik membawa bola dengan mengunakan kaki bagian dalam mau punggung kaki dengan tujuan untuk melewati musuh sehingga bisa mencetak gol (Sandi, C. A. K., Saptani, E., \& Suherman, 2009). Pengertian shooting adalah salah satu teknik untuk memasukan bola ke gawang dan menghasilkan gol (Istofian, R. S., \& Amiq, 2016), kemudian shooting adalah teknik yang bertujuan untuk mencetak angka dengan mengarahkan bola ke sasaran atau gawang (Rustendi, E., Rif'at, M., \& Hakim, 2014). Pengertian heading merupakan suatu teknik penguasaan bola memakai kepala dan bisa juga untuk penguasaan bola-bola atas (MAUJUD, n.d.) kemudian heading ialah suatu teknik dasar dalam bermain sepak bola yang menggunakan kepala untuk mengoper atau menerima bola dari teman agar bisa menciptakan gol (Hamzah, 2020).

Berdasarkan hasil analisis kebutuhan yang peneliti dapat dari pelatih yang dilakukan pada tanggal 26 februari 2021 di SSB Satria muda untuk pengetahuan tentang teknik dasar sepakbola, diketahui bahwa SSB Satria muda sudah berdiri sekitar 9 tahun dilakukan latihan 3 kali dalam seminggu yaitu hari selasa,jumat dan minggu latihan dilakukan selama 90 menit menurut pelatih tujuan untuk penguasaan teknik dasar sepakbola dan menunjang prestasi atlet, sehingga fokus pelatih adalah kualitas atlet SSB Satria muda baik dari segi teknik,taktik 
maupun mental dalam bermain sepakbola, khusus pada teknik dasar sepakbola yang terdiri dari passing, controlling, dribbling, shooting dan heading menurut pelatih masih banyak kesulitan yang dialami atlet dari hasil yang dipaparkan dapat disimpulkan bahwa perlu sekali adanya pengembangan model latihan teknik dasar sepakbola agar atlet dapat menguasai teknik dasar dengan baik dan bervariasi sehingga tujuan dalam latihan di SSB Satria muda dapat berjalan dengan baik dan maksimal. Olah karena itu peneliti tertarik untuk mengembangkan model latihan teknik dasar sepakbola untuk SSB Satria muda dengan adanya model latihan teknik dasar sepakbola ini diharapkan atlet dapat menguasai teknik dasar sepakbola dengan baik. Untuk itu maka akan mengadakan penelitian pengembangan dengan judul "Pengembangan Model Latihan Teknik Dasar Sepakbola Usia 14-15 Tahun Di SSB Satria Muda Kota Malang"

\section{Metode}

Metode penelitian yang digunakan dalam penelitian ini adalah Research and Development (R\&D) dengan model ADDIE dalam (Tegeh, Campbell, and Pudjawan 2014) yang mencakup analisis kebutuhan, perancangan produk, validasi ahli dan revisi, sehingga menghasilkan sebuah produk berupa model latihan teknik dasar sepakbola untuk SSB Satria muda, pengumpulan data dalam penelitian ini menggunakan angket yang diberikan kepada pelatih dan ahli kepelatihan sepakbola, analisis data dalam penelitian ini menggunakan deskriptif kualitatif dan kuantitatif yakni persentase.

\section{Hasil dan Pembahasan}

Pada penelitian ini, peneliti mengembangkan atau membuat produk sebanyak 25 model latihan teknik dasar sepakbola yang terdiri dari passing, controlling, dribbling, shooting dan heading.

\subsection{Produk Pengembangan Model Latihan Teknik Dasar Passing Dalam Sepak Bola}

Model latihan pertama adalah model latihan passing yang bertujuan untuk melatih meningkatkan akurasi passing atlet. Adapun contoh model latihan nya adalah passing berbalik badan, passing berpindah tempat (bergeser), passing berpindah tempat (memutar), passing dua arah, dan passing panjang dan pendek.

\subsubsection{Model latihan passing berbalik badan}

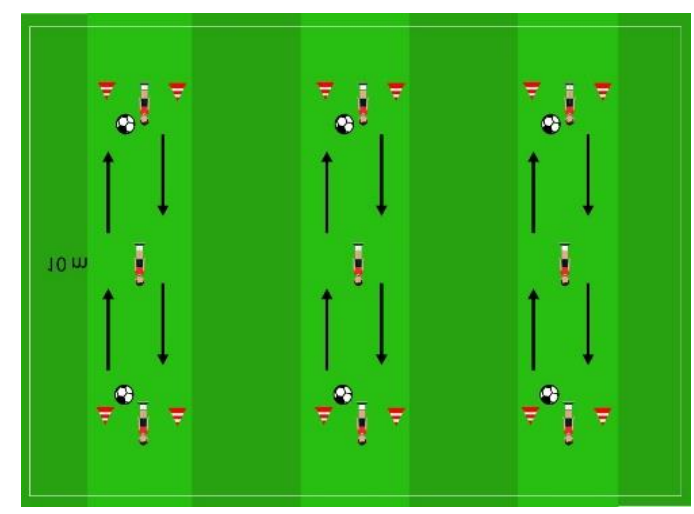

Gambar 1. Model Latihan Passing Berbalik Badan 
Pemain dibagi menjadi 3 kelompok, masing-masing kun diisi dengan 3 orang pemain, satu pemain berada di tengah sedangkan pemain yang lain berada di antara kun. selanjutnya pemain yang berada diantara kun melakukan passing menggunakan kaki bagian dalam ke pemain yang berada di tengah terus bola di passing balik pemain tengah berbalik badan untuk menerima passing berikutnya terus passing balik setiap pemain melakukan selama 3 menit dilakukan secara terus menerus dan bergantian.

\subsubsection{Model Latihan Passing Berpindah Tempat (Bergeser)}

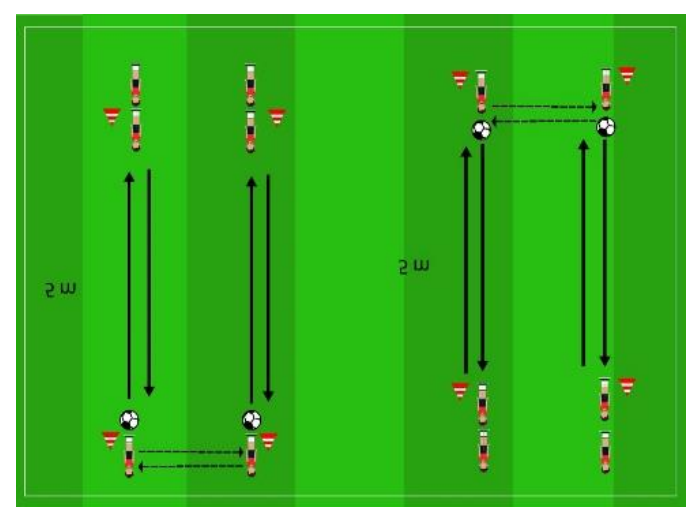

Gambar 2. Model Latihan Passing Berpindah Tempat (Bergeser)

Pemain dibagi menjadi 2 kelompok masing-masing kelompok terdiri dari 4 pemain pertama siapkan 4 kun pemain 1 dan 2 yang memegang bola melakukan passing menggunakan kaki bagian dalam ke pemain 3 dan 4 setelah itu pemain 1 dan 2 melakukan pergerakan saling menukar tempat pemain 3 dan 4 melakukan passing lagi ke pemain 1 dan 2 dilakukan selama 3 menit secara bergantian.

\subsubsection{Model latihan passing berpindah tempat (memutar)}

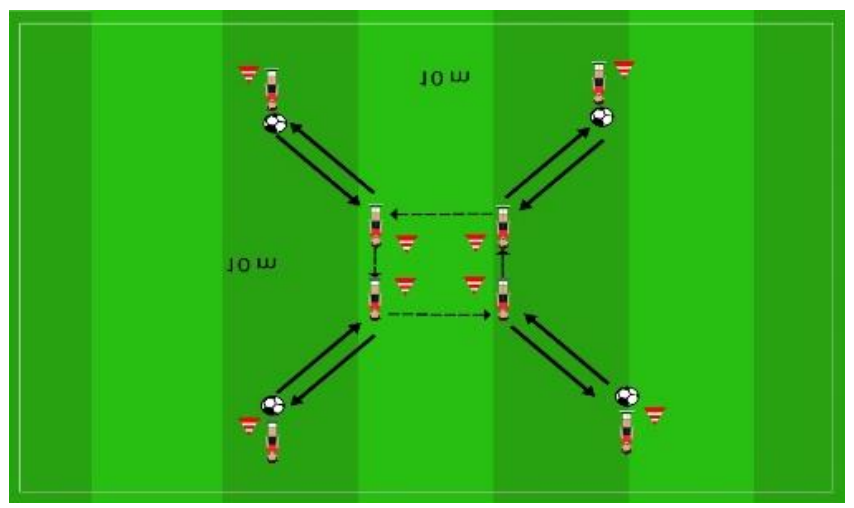

\section{Gambar 3. Model Latihan Passing Berpindah Tempat (Memutar)}

4 pemain berada di tengah isi kun sedangkan 4 pemain berada di kun luar,Pemain yang berada di kun luar melakukan passing menggunakan kaki bagian dalam ke pemain tengah, pemain tengah melakukan passing balik terus melakukan gerakan berganti posisi dilakukan selama 3 menit secara bergantian. 


\subsubsection{Model Latihan Passing Dua Arah}

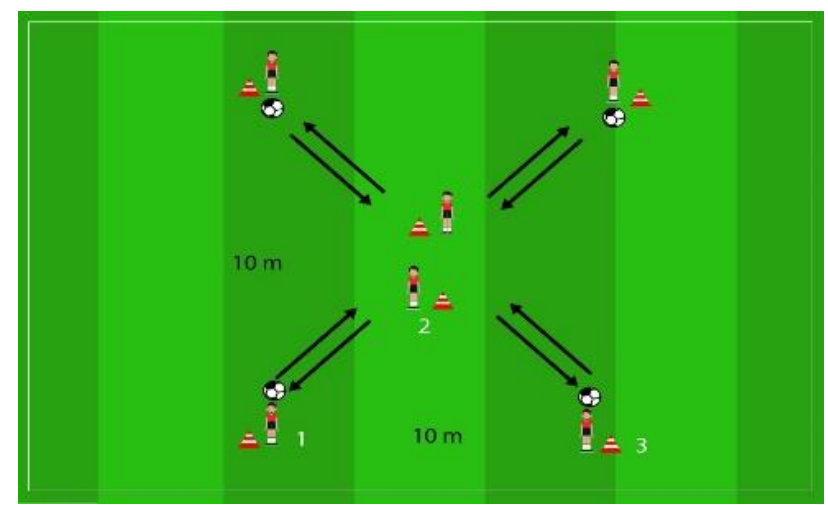

Gambar 4. Model Latihan Passing Dua Arah

Pemain berada di tengah sedangkan 4 pemain berada di kun Pemain 1 melakukan passing menggunakan kaki bagian dalam ke pemain 2 pemain dua passing balik ke pemain satu, pemain 3 melakukan passing ke pemain 2 pemain tengah passing balik ke pemain 3 dilakukan selama 2 menit secara bergantian.

\subsubsection{Model Latihan Passing Panjang Dan Pendek}

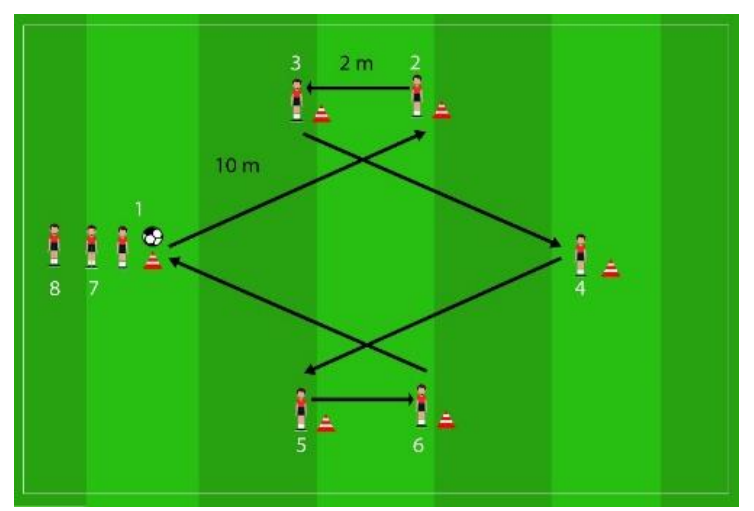

Gambar 5. Model Latihan Passing Panjang Dan Pendek

Pemain 1 yang memegang bola melakukan passing panjang menggunakan kaki bagian dalam ke pemain 2, Pemain 2 passing pendek ke pemain 3, pemain 3 passing panjang ke pemain 4 Begitu juga sebaliknya pemain 4 melakukan passing panjang ke pemain 5, pemain 5 passing pendek ke pemain 6 pemain enam melakukan passing ke pemain satu. Dilakukan selama 5 menit secara bergantian.

\subsection{Produk Pengembangan Model Latihan Teknik Dasar Control Dalam Sepak Bola}

Model latihan kedua adalah model latihan control yang bertujuan untuk melatih meningkatkan kualitas control atlet. Adapun contoh model latihan nya adalah control kaki dalam, control menggunakan paha, control berjalan, kontrol berjalan dua arah, dan control check-in check-out. 


\subsubsection{Model Latihan control kaki dalam}

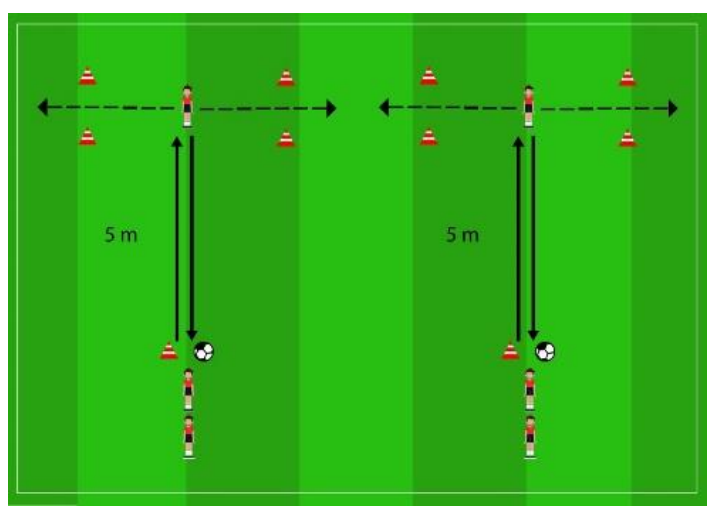

Gambar 6. Model latihan control kaki dalam

Pemain dibagi menjadi 2 kelompok masing-masing kelompok terdiri dari 2 pemain, pertama siapkan 5 kun pemain 1 berdiri diantara kun yang dibuat persegi empat pemain 2 melakukan passing kaki dalam ke pemain yang berada di dalam area kun pemain 1 mengontrol bola dengan kaki dalam terus melakukan passing ke pemain 2 pemain 1 melakukan gerakan ke kanan maupun ke kiri dilakukan selama 3 menit secara bergantian. 5 passing pendek ke pemain 6 pemain enam melakukan passing ke pemain satu. Dilakukan selama 5 menit secara bergantian.

\subsubsection{Model Latihan Control Menggunakan Paha}

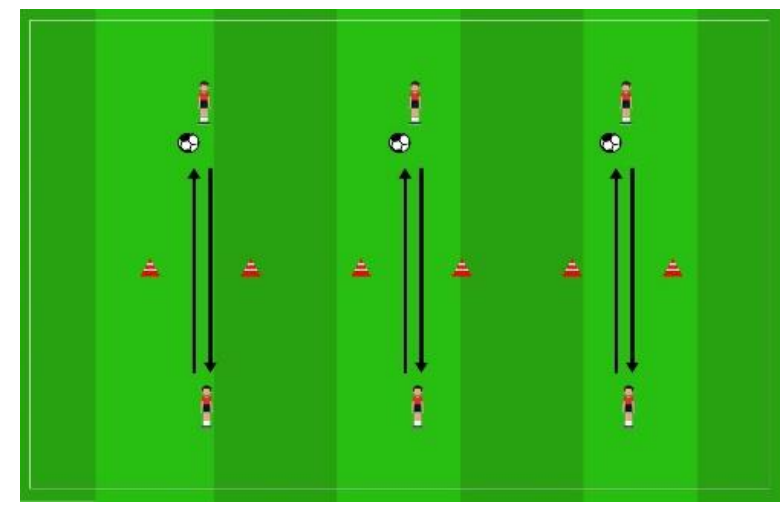

Gambar 7. Model Latihan Control Menggunakan Paha

Pemain dibagi menjadi 3 kelompok masing-masing kelompok terdiri dari 2 pemain, pertama siapkan 4 kun pemain 1 melakukan lemparan bola ke pemain dua diantara kun kemudian pemain 2 mengontrol bola menggunakan paha terus sebaliknya pemain 2 melakukan lemparan diantara kun pemain 1 mengontrol bola menggunakan paha dilakukan selama 3 menit secara terus menerus. 


\subsubsection{Model Latihan Control Berjalan}

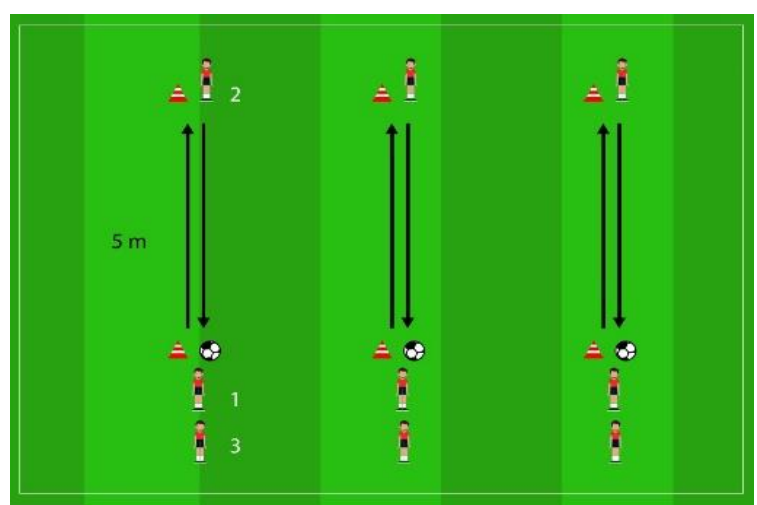

Gambar 8. Model Latihan Control Berjalan

Pemain membentuk 3 kelompok masing masing kelompok terdiri dari 3 pemain pemain 1 melakukan passing kaki dalam ke pemain 2, pemain 2 mengontrol bola menggunakan kaki dalam kemudian pemain 1 melakukan lari ke arah kun pemain 2 Kemudian pemain 2 melakukan passing ke pemain 3 pemain 2 lari ke arah kun pemain 3 dilakukan selama 5 menit secara terus menerus dan bergantian.

\subsubsection{Model Latihan Control Bejalan Dua Arah}

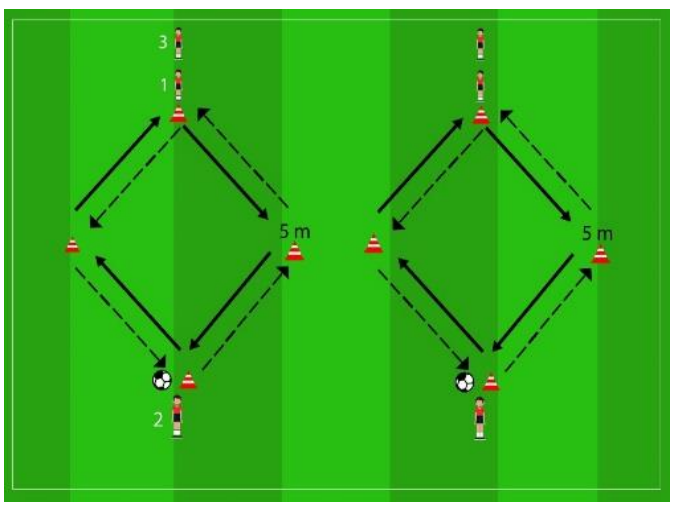

\section{Gambar 9. Model Latihan Control Berjalan Dua Arah}

Pemain membentuk 2 kelompok masing masing kelompok terdiri dari 4 pemain pemain 1 melakukan pergerakan ke ke arah kun yang kosong pemain 2 melakukan passing kaki dalam ke pemain 1 lalu mengontrol menggunakan kaki bagian dalam pemain 1 passing melakukan passing ke pemain 3 pemain 2 melakukan pergerakan ke antara kun pemain 1 mengisi kun pemain 2 dilakukan selama 5 menit secara bergantian. 


\subsubsection{Model Latihan Control Check-In Check Out}

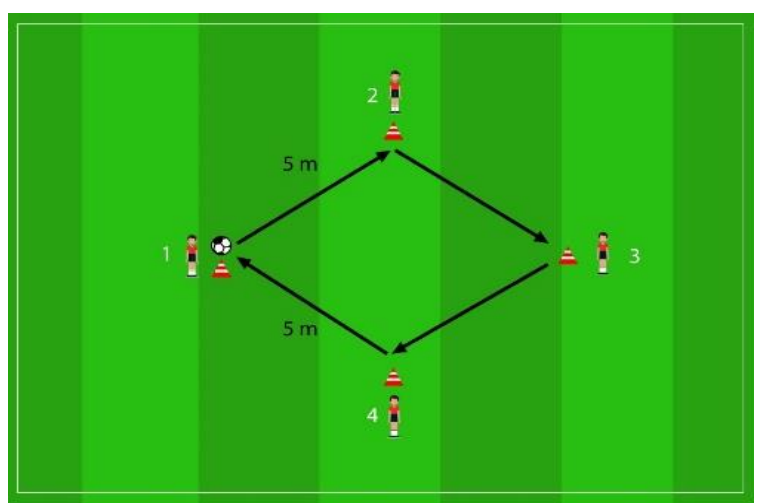

Gambar 10. Model Latihan Control Check-In Check Out

Pemain membentuk persegi empat pemain 1 melakukan passing kaki dalam ke pemain 2 melakukan check-in check-out lalu mengontrol bola menggunakan kaki dalam Pemain 2 melakukan passing ke pemain 3, pemain 3 melakukan check-in check-out lalu mengontrol bola begitu juga pemain 4 Dilakukan secara terus menerus selama 5 menit dan bergantian.

\subsection{Produk Pengembangan Model Latihan Teknik Dasar Dribbling Dalam Sepak Bola}

Model latihan ketiga adalah model latihan dribbling yang bertujuan untuk melatih meningkatkan kualitas dribbling dengan pergerakan atlet. Adapun contoh model latihan nya adalah dribbling menggunakan punggung kaki, dribbling berpindah tempat (menyilang), dribbling caping (kaki dalam), dribbling zigzag, dan dribbling berpindah tempat.

\subsubsection{Model Latihan Dribbling Menggunakan Punggung Kaki}

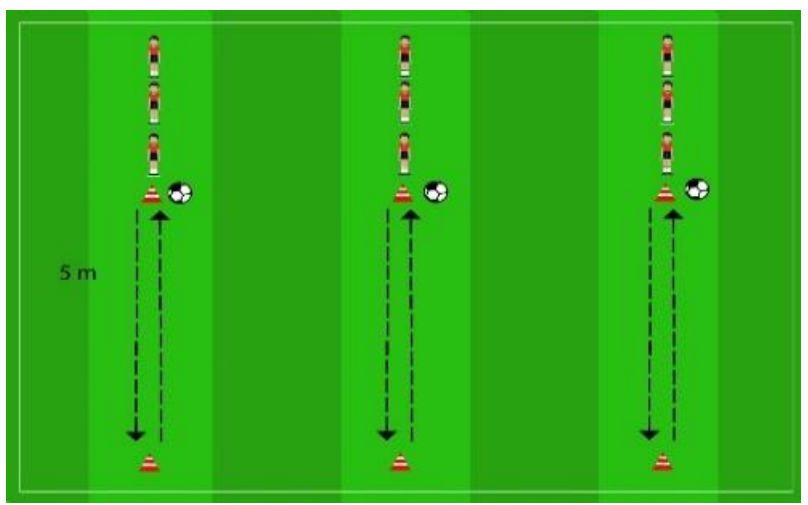

Gambar 11. Model Latihan Dribbling Menggunakan Punggung Kaki

Pemain dibagi menjadi 4 kelompok masing-masing kelompok terdiri dari 2 pemain pertama siapkan 8 kun semua pemain melakukan dribbling bola menggunakan punggung kaki ke arah kun yang berada di depan lalu memutarnya kembali ke posisi awal diganti orang selanjutnya dilakukan secara terus menerus selama 5 menit dan bergantian. 


\subsubsection{Model Latihan Dribbling Berpindah Tempat (Menyilang)}

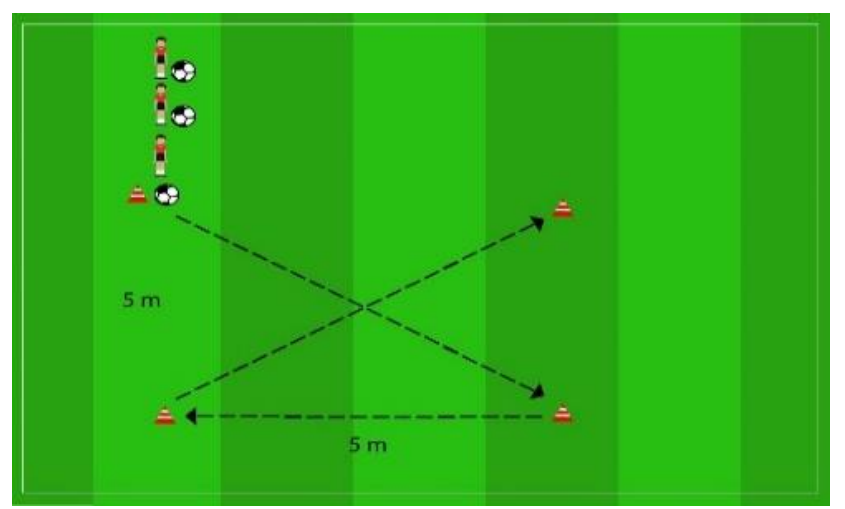

\section{Gambar 12. Model Latihan Dribbling Berpindah Tempat (Menyilang)}

Siapkan 4 kun bentuk sesuai yang ada di gambar Semua pemain berada di kun 1 dilakukan secara bergantian lalu melakukan dribbling menggunakan punggung kaki ke arah kun 2 lalu memutarinya dilanjutkan dribbling ke kun 3 memutarinya kemudian dribbling ke kun 4 kemudian stop dilanjutkan pemain berikutnya dilakukan secara terus menerus selama 5 menit dan bergantian

\subsubsection{Model Latihan Dribbling Caping (Kaki Dalam)}

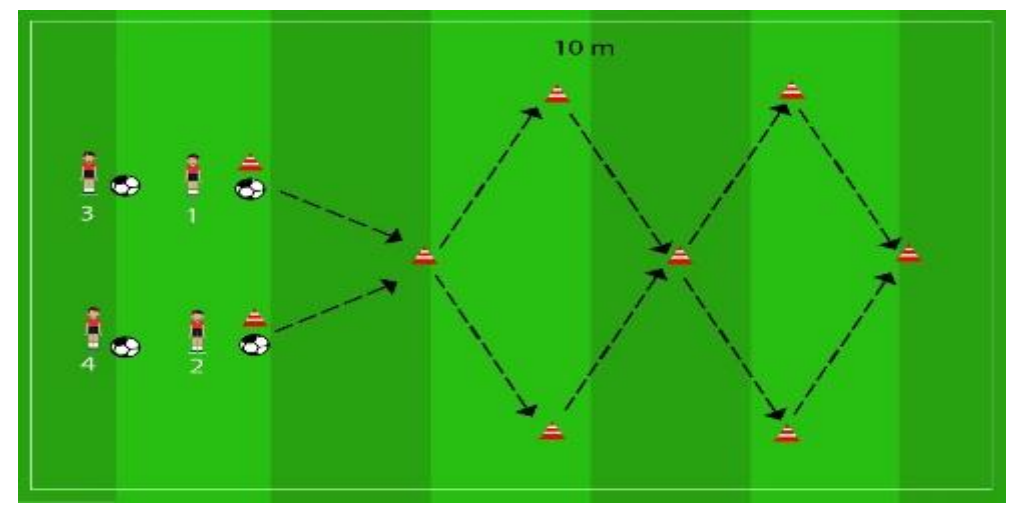

Gambar 13. Model Latihan Dribbling Caping (Kaki Dalam)

Pemain 1 dan 2 secara bersama melakukan dribbling punggung kaki melewati kun yang sudah dibentuk setelah selesai, pemain 1 dan 2 langsung passing bola ke pemain 3 dan 4 dilakukan secara terus menerus selama 5 menit dan bergantian. 


\subsubsection{Model Latihan Dribbling Zigzag}

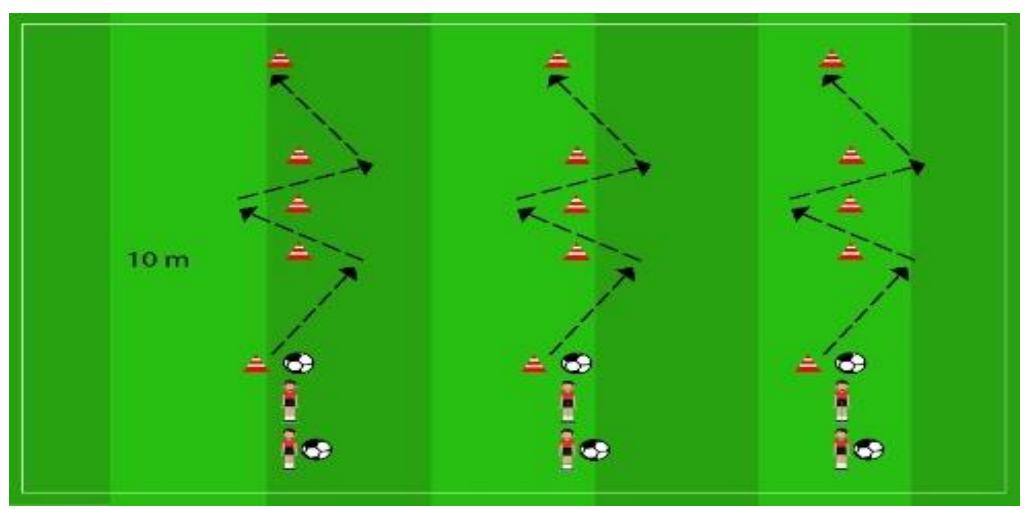

Gambar 14. Model Latihan Zigzag

Bentuk 3 kelompok masing- masing kelompok 2 pemain, pemain melakukan dribbling zigzag menggunakan punggung kaki melewati akun ketika pemain pertama sudah selesai melakukan dilanjutkan pemain berikutnya dilakukan terus menerus selama 5 menit dan bergantian.

\subsubsection{Model Latihan Dribbling Berpindah Tempat}

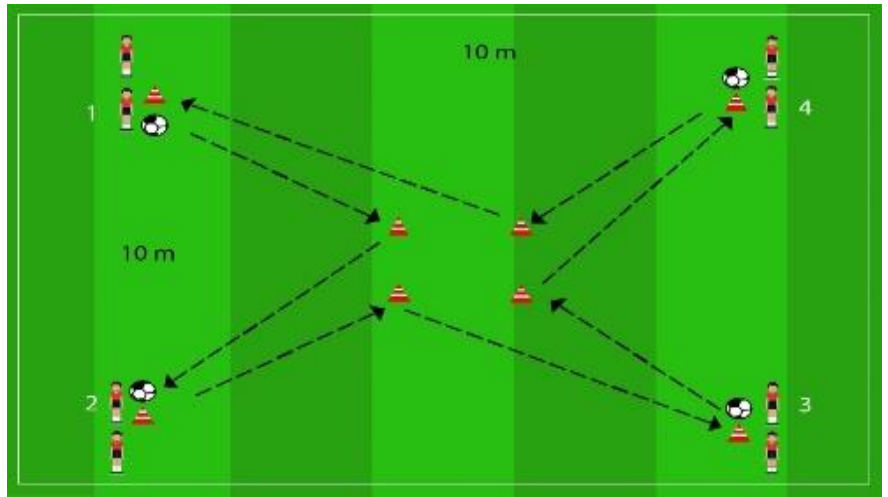

Gambar 15. Model Latihan Dribbling Berpindah Tempat

Pemain 1,2,3 dan 4 melakukan gerakan dribbling menggunakan punggung kaki secara bersama ke arah kun yang berada di tengah ketika sampai di tengah pemain 1 bergeser ke posisi pemain 2 pemain dua sebaliknya juga ke posisi pemain 3 dilakukan terus menerus selama 5 menit secara bergantian.

\subsection{Produk Pengembangan Model Latihan Teknik Dasar Shooting Dalam Sepak Bola}

Model latihan keempat adalah model latihan shooting yang bertujuan untuk melatih meningkatkan kualitas shooting dan respon yang cepat untuk melakukan shooting ke arah gawang. Adapun contoh model latihan nya adalah shooting passing true pass, shooting dan passing panjang, shooting passing overlap, shooting berbalik badan, dan shooting kombinasi zigzag. 


\subsubsection{Model Latihan Shooting Passing True pass}

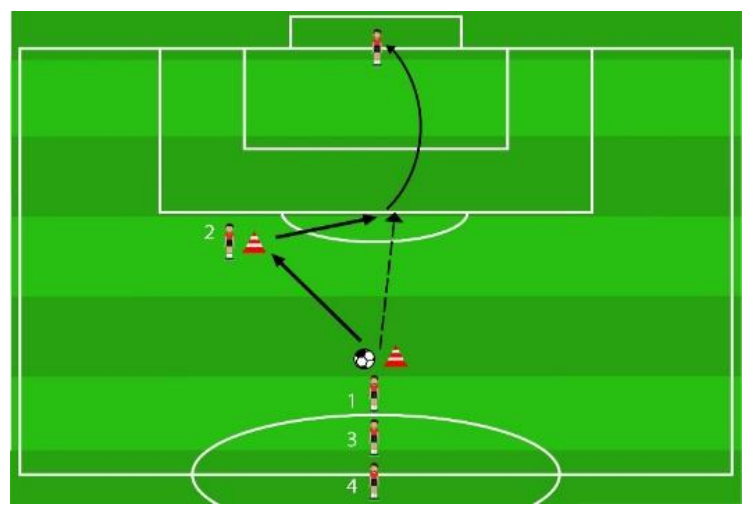

Gambar 16. Model Latihan Shooting Passing True pass

Siapkan 2 kun lalu semua pemain berada di kun 1 sedangkan di kun 2 hanya 1 pemain sebagai pemantul bola, pemain 1 melakukan passing kaki dalam ke pemain 2 selanjutnya pemain 2 melakukan passing atau pantulan pemain 1 melakukan larian kecil kemudian shooting menggunakan punggung kaki ke arah gawang dilakukan secara bergantian selama 10 menit.

\subsubsection{Model Latihan Shooting Dan Passing Panjang}

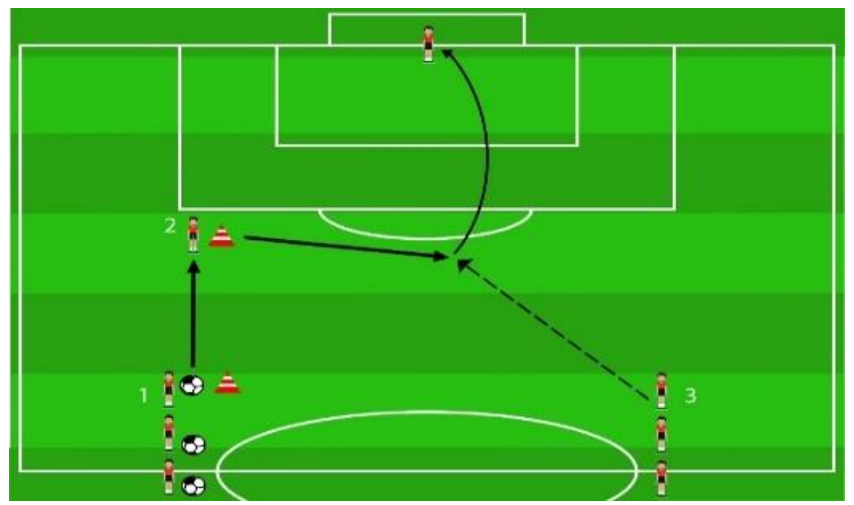

Gambar 17. Model Latihan Shooting Dan Passing Panjang

Siapakan 3 kun, kun 1 dan 2 di isi masing-masing 3 Pemain sedangkan kun 3 hanya diisi 1 orang pemain, pemain 1 melakukan passing kaki dalam ke pemain 3 kemudian pemain 3 melakukan passing ke tengah pemain 2 melakukan pergerakan lalu melakukan shooting menggunakan punggung kaki ke arah gawang, dilakukan secara bergantian selama 10 menit. 


\subsubsection{Model Latihan Shooting Passing Overlap}

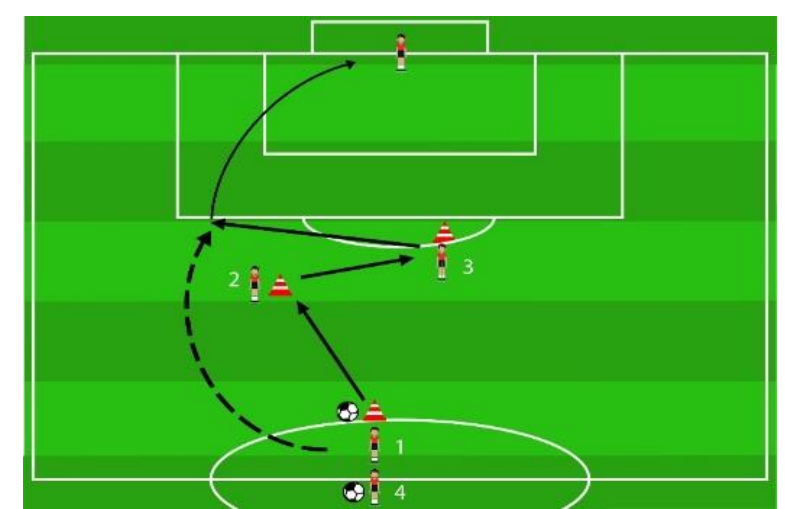

Gambar 18. Model Latihan Shooting Passing Overlap

Pemain 1 melakukan passing ke pemain 2 pemain 2 melakukan passing kaki dalam ke pemain 3 kemudian pemain 3 melakukan passing pendek ke depan gawang pemain 1 melakukan pergerakan ke arah bola kemudian langsung shooting menggunakan punggung kaki ke arah gawang dilanjutkan pemain berikutnya, dilakukan selama 10 menit secara bergantian.

\subsubsection{Model Latihan Shooting Berbalik Badan}

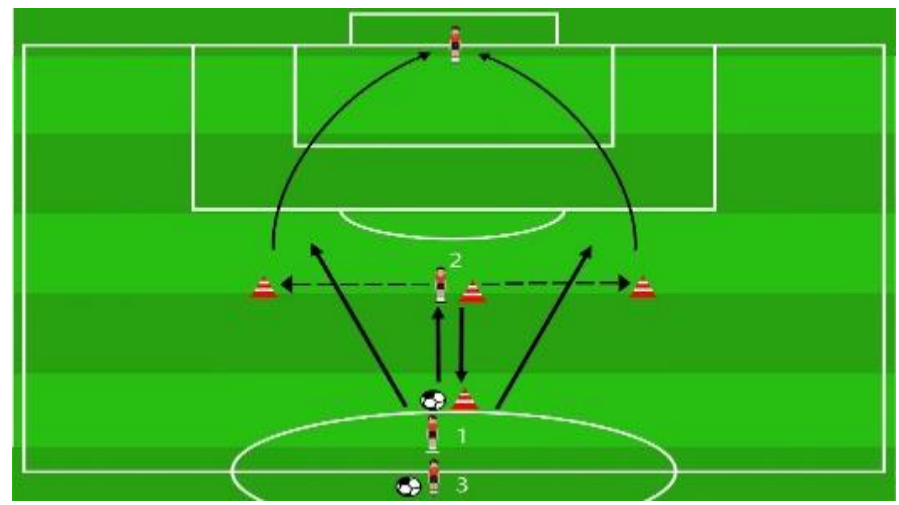

Gambar 19. Model Latihan Shooting Berbalik Badan

Pemain 1 melakukan passing kaki dalam ke pemain 2 kemudian pemain 2 passing balik ke pemain 1, pemain 1 through pass ke kanan maupun ke kiri pemain 2 berbalik badan dan siap untuk melakukan shooting menggunakan punggung kaki ke arah gawang dilanjutkan pemain berikutnya dilakukan selama 10 menit secara bergantian. 


\subsubsection{Model Latihan Shooting Kombinasi Zigzag}

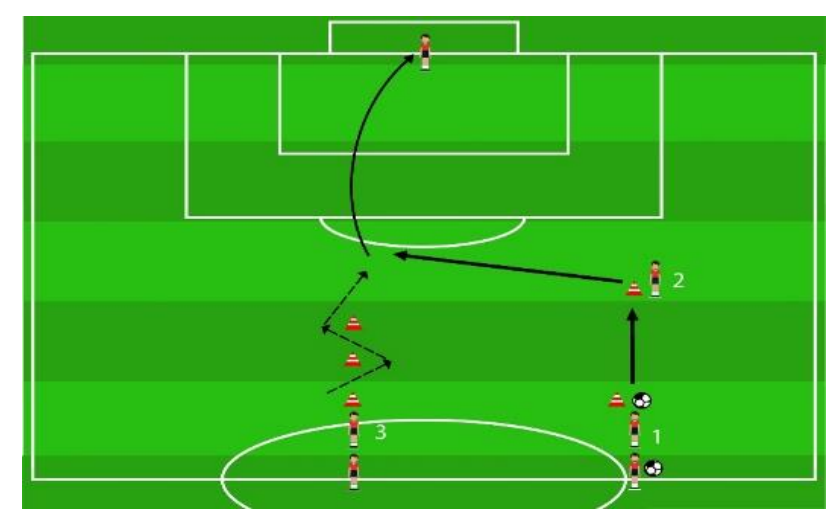

Gambar 20. Model Latihan Shooting Kombinasi Zigzag

Pemain 1 melakukan passing kaki dalam ke pemain 2 kemudian pemain 2 melakukan passing pendek ke arah depan gawang Pemain 3 melakukan zigzag melewati kun kemudian lari ke arah bola untuk melakukan shooting menggunakan punggung kaki dilanjutkan pemain berikutnya dilakukan selama 10 menit secara bergantian.

\subsection{Produk Pengembangan Model Latihan Teknik Dasar Heading Dalam Sepak Bola}

Model latihan kelima adalah model latihan heading yang bertujuan untuk melatih meningkatkan kualitas heading dengan pergerakan atlet. Adapun contoh model latihan nya adalah heading dengan awalan zigzag, heading dengan pergerakan kedepan, heading berpasangan, heading dengan lompatan, heading bergantian.

\subsubsection{Model Latihan Heading Dengan Awalan Zigzag}

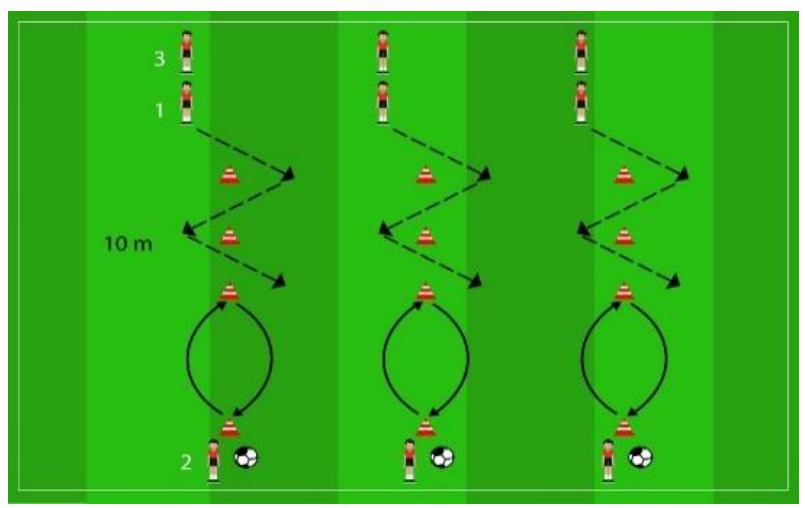

Gambar 21. Model Latihan Heading Dengan Awalan Zigzag

Pemain dibagi menjadi 3 kelompok masing-masing kelompok terdiri dari 2 pemain yang pertama siapkan 12 kun semua pemain melakukan pergerakan zigzag ke arah pemain yang memegang bola kemudian apabila sudah mendekati, pemain yang memegang bola melakukan lemparan ke arah pemain telah melakukan zigzag kemudian pemain 1 melakukan heading kepala sebanyak 10 kali secara bergantian. 


\subsubsection{Model Latihan Heading Dengan Pergerakan Kedepan}

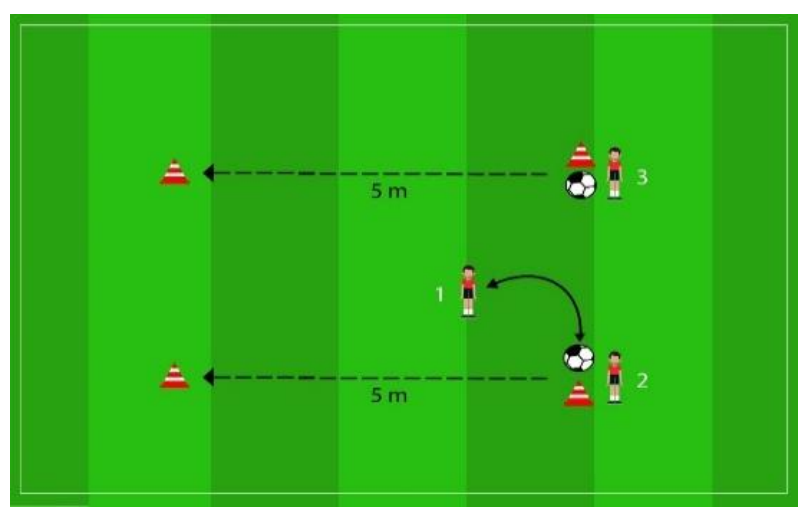

\section{Gambar 22. Model Latihan Heading Dengan Pergerakan Kedepan}

Siapkan 4 kun Pemain 1 berada di antara pemain 2 dan 3 kemudian pemain 2 melakukan lemparan ke arah pemain 1 untuk melakukan heading kepala dilakukan pergerakan dari akun ke akun kemudian setelah selesai, pemain 1 melakukan pergerakan ke pemain 3, pemain 3 melakukan lemparan ke arah pemain 1 untuk melakukan heading, dilakukan secara terus menerus dan bergantian.

\subsubsection{Model Latihan Heading Berpasangan}

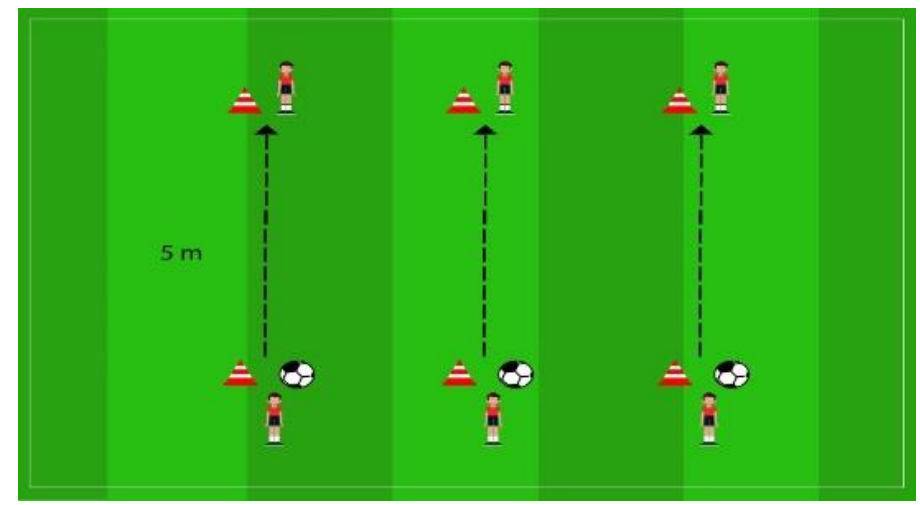

Gambar 23. Model Latihan Heading Berpasangan

Pemain dibagi menjadi 3 kelompok masing- masing kelompok 2 pemain pemain yang memegang bola melakukan lemparan ke arah depan kemudian pemain yang tidak memegang bola melakukan heading kepala dilakukan 1 pemain 10 kali heading saling bergantian. 


\subsubsection{Model Latihan Heading Dengan Lompatan}

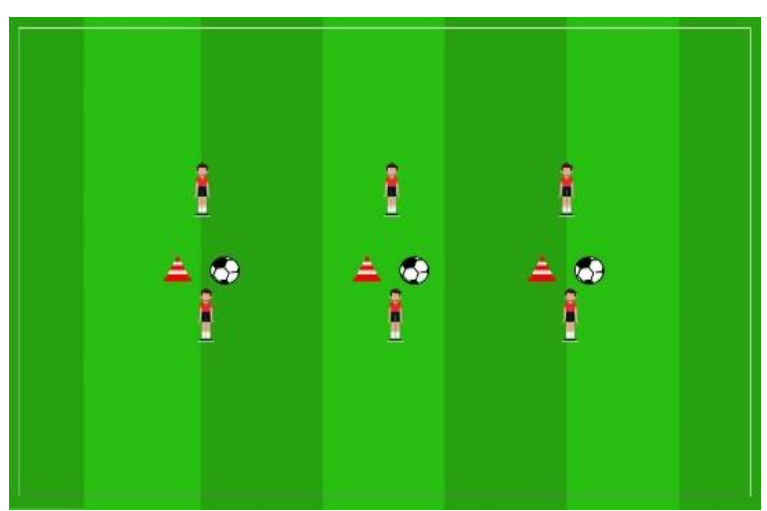

Gambar 24. Model Latihan Heading Dengan Lompatan

Pemain dibagi menjadi 3 kelompok masing- masing kelompok 2 pemain, pemain yang memegang bola mengangkat bola di atas kepalanya pemain yang tidak memegang bola melakukan heading sebanyak 10 kali dilakukan secara bergantian apabila sudah 10 kali heading.

\subsubsection{Model Latihan Heading Bergantian}

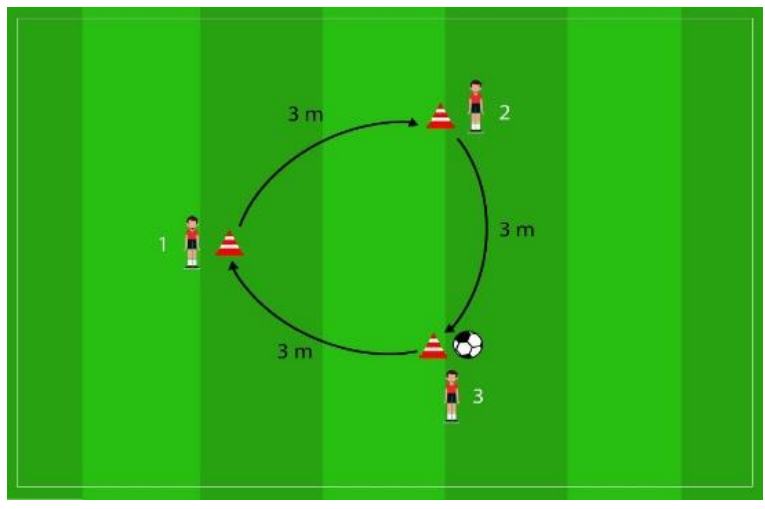

Gambar 25. Model Latihan Heading Bergantian

Pemain 1 melakukan lemparan ke pemain 2 pemain 2 melakukan heading kepala ke pemain 3 kemudian ditangkap pemain 3 melakukan lemparan ke pemain 1, pemain 1 melakukan heading kepala ke pemain 2, pemain 2 melakukan tangkapan kemudian melempar ke pemain 3, pemain 3 heading ke pemain 1 dilakukan terus menerus selama 3 menit secara bergantian.

Tabel 6. Hasil Validasi Ahli Kepelatihan Sepakbola 1

\begin{tabular}{llllll}
\hline No & Sub Variabel & Skor perolehan & Skor Maksimal & Skor persentase & Keterangan \\
\hline 1 & Kesesuaian & 25 & 26 & $96,15 \%$ & Sangat baik \\
2 & Kemudahan & 26 & 26 & $100 \%$ & Sangat baik \\
3 & Kemenarikan & 26 & 26 & $100 \%$ & Sangat baik \\
\hline & \multirow{2}{*}{ Total } & 77 & 78 & $98,71 \%$ & Sangat baik \\
\hline
\end{tabular}


Tabel 7. Hasil Validasi Ahli Kepelatihan Sepakbola 2

\begin{tabular}{llllll}
\hline No & Sub Variabel & Skor perolehan & Skor Maksimal & Skor persentase & Keterangan \\
\hline 1 & Kesesuaian & 26 & 26 & $100 \%$ & Sangat baik \\
2 & Kemudahan & 26 & 26 & $100 \%$ & Sangat baik \\
3 & Kemenarikan & 26 & 26 & $100 \%$ & Sangat baik \\
\hline \multirow{2}{*}{ Total } & \multirow{2}{*}{78} & 78 & \multirow{2}{*}{$100 \%$} & Sangat baik \\
\hline
\end{tabular}

Tabel 8. Hasil Validasi Ahli Kepelatihan Sepakbola 3

\begin{tabular}{llllll}
\hline No & Sub Variabel & Skor perolehan & Skor Maksimal & Skor persentase & Keterangan \\
\hline 1 & Kesesuaian & 26 & 26 & $100 \%$ & Sangat baik \\
2 & Kemudahan & 26 & 26 & $100 \%$ & Sangat baik \\
3 & Kemenarikan & 26 & 26 & $100 \%$ & Sangat baik \\
\hline \multirow{2}{*}{ Total } & 78 & 78 & \multirow{2}{*}{$100 \%$} & Sangat baik \\
\hline
\end{tabular}

Dari hasil validasi 3 ahli kepelatihan sepakbola memperoleh hasil nilai 99,57 \% menyatakan model latihan ini dapat digunakan sehingg dapat disimpulkan bahwa hasil produk ini layak dan dapat digunakan untuk atlet usia 14-15 tahun SSB Satria Muda Kota Malang. Pelaksanaan latihan dilaksanakan 3 kali dalam 1 minggu yaitu pada hari selasa, jumat dan minggu. teknik dasar sepakbola di SSB Satria muda kurang bervariasi, hal tersebut dapat diketahui saat melakukan analisis kebutuhan kepada pelatih dengan menggunakan metode wawancara dan angket Teknik dasar adalah salah satu hal yang mendasar dalam permainan sehingga dengan teknik dasar tersebut menjadi modal pemain untuk dapat bermain sepakbola. (Saputra et al., 2019) menyatakan kemampuan teknik dasar sepakbola menjadi salah satu pondasi untuk seorang pemain agar bisa bermain sepakbola dengan baik. Sedangkan menurut (Astuti dkk 2020) teknik dasar sepakbola yaitu kegiatan yang mendasar bagi permainan dengan modal seperti itu atlet sudah bisa bermain sepakbola.

Kurangnya variasi latihan mengenai teknik dasar sepakbola menjadi salah satu kendala untuk perkembangan atlet pada saat melakukan materi latihan yang sudah disusun oleh pelatih. Pengembangan model latihan teknik dasar biasanya dianggap sepele pada saat latihan. Pada saat seperti, ini teknik dasar menjadi salah satu hal penting yang wajib dikuasai atlet sepakbola. Untuk menguasai teknik dasar sepakbola sangatlah dibutuhkan model latihan yang bervariasi. Pengembangan model latihan ialah suatu proses dalam jangka panjang yang dilakukan dengan kontinu dan akan berubah terus menerus dikarenakan model latihan dapat berkembang sesuai perkembangan atletnya (Lubis 2013:20). Pelatih berusaha mengorganisasikan dan memimpin waktu latihan dengan cara yang lebih objektif, dengan metode dan isi yang di buat sama dengan situasi pertandingan Melalui model latihan. Menurut (Falah, 2019) latihan mengunakan model latihan yang bervariasi akan membuat atlet lebih serius atau giat dalam melakukan latihan sehingga tidak membuat atlit merasa bosan dengan latihan monoton.

Dalam proses latihan atlet sepakbola SSB Satria Muda sangat diperlukan pengembangan model latihan teknik dasar permainan sepakbola sebagai penunjang. Hal tersebut dapat disimpulkan dari hasil wawancara kepada pelatih yang menyatakan bahwa pelatih memerlukan model latihan untuk menambah antusias atlet, sehingga atlet terhindar dari 
kebosanan pada saat latihan. Penguasaan teknik dasar sangatlah berpengaruh terhadap kemampuan atlet dalam bermain sepakbola. Menurut (Radita Dwi Candra, Sulaiman 2015) teknik dasar adalah suatu syarat untuk seorang pemain dapat bermain sepakbola. Hal ini sama seperti yang dijelaskan oleh (Handoko, 2018) seorang atlet sangat diharuskan mempunyai kemampuan teknik dasar sepakbola yang baik supaya dapat menciptakan permainan yang baik dan maksimal. sebab itu kemampuan teknik dasar menjadi salah satu hal yang wajib dimiliki oleh seorang atlet sepakbola.

Peneliti sudah membaca dan menganalisis dari peneliti sebelumnya dari Setiawan yaitu Model Latihan Heading Sepakbola Berbasis Sirkuit Pada Sekolah Sepakbola Usia 14-17 Tahun, dimana penelitian hanya berisi model latihan heading sepakbola (Setiawan, 2019). Sedangkan penelitian yang dikembangkan peneliti berisi model latihan teknik dasar sepakbola mulai dari passing, control, dribbling, shooting dan heading. Perbedaan peneliti sebelumnya adalah variabel, dimana peneliti sebelumnya hanya menggunakan 1 variabel yaitu heading sedangkan penelitian ini menggunakan 5 variabel yaitu passing, control, dribbling, shooting dan heading.

Produk pengembangan ini adalah pengembangan model latihan teknik dasar sepakbola untuk atlet usia 14-15 tahun di SSB Satria muda kota malang. Di dalam model latihan ini terdapat 25 model latihan yang terdiri dari passing, controlling, dribbling, shooting dan heading dengan masing-masing terdiri 5 model latihan. Model latihan ini sudah di sesuaikan dengan kebutuhan dan kemampuan atlet usia 14-15 tahun. Produk penelitian ini memiliki kelebihan diantaranya memberikan gambaran lengkap tentang model latihan teknik dasar sepak bola serta memiliki model latihan yang lebih bervariasi.

\section{Simpulan}

Berdasarkan penelitian dan pengembangan yang berjudul "Pengembangan Model Latihan Teknik Dasar Sepakbola Usia 14-15 Tahun Di SSB Satria Muda Kota Malang" Menghasilkan sebanyak 25 model latihan yang terdiri dari passing, controlling, dribbling, shooting dan heading.

\section{Daftar Rujukan}

Amiq, F. (2016). Sepak bola (sejarah pengembangan, teknik dasar, persiapan kondisi fisik, peraturan permainan, dan strategi bermain). Universitas Negeri Malang.

Aprianova, F., \& Hariadi, I. (2017). Metode Drill Untuk Meningkatkan Teknik Dasar Menggiring Bola ( Dribbling ) Dalam Permainan Sepakbola Pada Siswa Sekolah Sepakbola Putra Zodiac Kabupaten Bojonegoro Usia 13-15 Tahun. Indonesia Performance Journal, 1(1), 63-74.

Astuti, Y. (2020). Studi Keterampilan Teknik Dasar Sepakbola Siswa Smp Negeri 3 Kota Padang. 8.

Bangun, S. Y. (2016). Peran Pendidikan Jasmani Dan Olahraga Kajian Pustaka \& Pembahasan. VI.

Chan, F. (2012). Strength Training (Latihan Kekuatan) Oleh : Faizal Chan, PORKES FKIP Universitas Jambi menempuh parameter dan alur periodisasi Adapun dalam periodesasi latihan strength terdiri : 1 . Fase Adaptasi Anatomi 3 . fase conversion 5. Fase transition Fase pe. 1, 1-8.

PSSI, H. P. U. (2017). Kurikulum Pembinaan Sepakbola Indonesia. Persatuan Sepakbola Seluruh Indonesia.

Fadli, M. (2019). Survei Tingkat Kemampuan Teknik Dasar Bermain Sepakbola Pada Pemain Usia 14-16 Tahun Di Sekolah Sepakbola (SSB) Persis Makassar.

Falah, S. A. (2019). Pengembangan Variasi Model-Model Latihan Agility Sepakbola. 1(2), 139-145.

Ferianto, B., Kuntjoro, T., Studi, P., Jasmani, P., \& Surabaya, U. N. (2020). Rasisme dalam olahraga. 7(1), 69-77.

Hamzah, M. N. (2020). Hubungan Daya Ledak Otot Tungkai Dan Kelentukan Otot Pinggang Terhadap Kemampuan Heading Sepakbola Atlet Klub Gama Fc Tembilahan Kabupaten Indragiri Hilir. Jurnal Olahraga Indragiri, 6, 1-10. 
Handoko, A. H. (2018). Analisis Kemampuan Teknik Dasar Pemain Sepak Bola SSB Deli Serdang United Kabupaten Deli Serdang. Jorpres (Jurnal Olahraga Prestasi), 14(1), 64-80. https://doi.org/10.21831/jorpres.v14i1.19982

Istofian, R. S., \& Amiq, F. (2016). Metode drill untuk meningkatkan teknik menendang Bola ( Shooting) dalam permainan sepakbola usia 13-14 tahun Jurnal Kepelatihan Olahraga. Jurnal Kepelatihan Olahraga, 1(1), $105-113$.

Julianto, A. R., Rusmiati, P., \& Suryadi, D. (2019). Upaya Meningkatkan Hasil Belajar Passing dan Control Sepak Bola menggunakan Metode Permainan. In Prosiding Seminar Nasional Pendidikan STKIP Kusuma Negara.,1-7.

Khairuddin, K. (2017). Olahraga Dalam Pandangan Islam. Jurnal Olahraga Indragiri, 1(1), 1-14.

Lubis, J. (2013). Panduan Praktis Penyusunan Program Latihan. PT. Rajagrafindo Persada.

Maujud, M. F. (2017). Survei Keterampilan Dribbling, Shootng 1, Heading Dan Throw in Pada Ssb Yudha Bhirawa U-14 Kecamatan Tugu Trenggalek Survey Dribbling Skill, Shooting, Heading and Throw In The Ssb Yudha Bhirawa U-14 District Of Tugu Trenggalek.

Palar, C. M., Wongkar, D., \& Ticoalu, S. H. R. (2015). Manfaat Latihan Olahraga Aerobik Terhadap Kebugaran Fisik Manusia. Jurnal E-Biomedik, 3(1). https://doi.org/10.35790/ebm.3.1.2015.7127

Qohhar, W., \& Pazriansyah, D. (2019). Pengaruh Model Pembelajaran Kooperatif Tipe Teaching Games For Understanding (TGFU) Terhadap Peningkatan Hasil Belajar Teknik Dasar Sepakbola. Physical Activity Journal ( PAJU ), 1(1), 27-35. http://jos.unsoed.ac.id/index.php/paju/article/view/2005/1184

Candra, R. D., \& Hidayah, T. (2015). Pengaruh metode latihan dan kemampuan motor educability terhadap hasil latihan teknik dasar sepakbola. Journal of Physical Education and Sports, 4(2), 159-164.

Rustendi, E., Rif'at, M., \& Hakim, A. F. (2014). Upaya Meningkatkan Kemampuan Shooting Permainan Sepakbola Menggunakan Metode Modifikasi Permainan pada Siswa Kelas VIII SMP Negeri 05 Sayan Tahun Pelajaran 2011/2012. Jurnal Pendidikan Jasmani Kesehatan Dan Rekreasi, 1(1), 75-78.

Sandi, C. A. K., Saptani, E., \& Suherman, A. (2009). Pengaruh Metode Latihan Kelincahan Terhadap Keterampilan Dribbling Bola Pada Permainan Sepakbola. SpoRTIVE, 3(1), 41-50. https://ejournal.upi.edu/index.php/SpoRTIVE/article/view/13337

Santoso, N. (2014). Tingkat Keterampilan Passing-Stoping Dalam Permainan Sepakbola Pada Mahasiswa Pjkr B Angkatan 2013. Jurnal Pendidikan Jasmani Indonesia, Volume 10,(November), 40-48.

Saputra, M. R. E., \& Yunus, M. (2019). Pengembangan Variasi Model Latihan Dribbling Sepakbola untuk Atlet Usia 13-15 Tahun. Indonesia Performance Journal, 3(1), 8-15.

Saputra, A., Muzaffar, A., Alpaizin, M., \& Wibowo, Y. G. (2019). Analisis Kemampuan Teknik Dasar Pemain Sepak Bola Ssb Pratama Kabupaten Batanghari. Indonesian Journal of Sport Science and Coaching, 1(1), 1-10. https://doi.org/10.22437/ijssc.v1i1.6311

Nosa, A, S. S. (2013). Survei Tingkat Kebugaran Jasmani Pada Pemain Persatuan Sepakbola Indonesia Lumajang. Jurnal Prestasi Olahraga, 1(1), 1-8.

Setiawan, R. R. (2019). Model Latihan Heading Sepakbola Berbasis Sirkuit pada Sekolah Sepakbola Usia 14-17 Tahun. Jurnal Terapan Ilmu Keolahragaan, 4(2), 133-136. https://doi.org/10.17509/jtikor.v4i2.19034

Simanjorang, E. K., Spyanawati, N. L. P., Pendidikan, P., Kesehatan, J., \& Olahraga, F. (2020). Pengembangan Video Tutorial Materi Passing Sepakbola Mata Pelajaran Pjokuntuk Kelas X SMA / SMK. 8(3).

Syukur, A., \& Soniawan, V. (n.d.). The Effects of Training Methods and Achievement Motivation Toward Of Football Passing Skills. 73-84.

Tegeh, I. made, Campel, I. nyoman, \& Pudjawan, K. (2014). Model Penelitian Pengembangan (cetakan pe). Graha Ilmu.

Rohman, U. (2017). Evaluasi Kompetensi Pelatih Sepakbola Usia Dini Di Sekolah Sepakbola. 2(September), 92104.

Wibowo, H. B. (2012). Surve pola pembinaan sekolahbola di kabupaten batang. 1(1). 